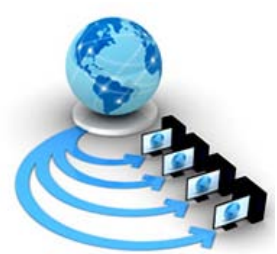

Volume 9, No. 2, March-April 2018

ISSN No. 0976-5697

International Journal of Advanced Research in Computer Science

RESEARCH PAPER

\author{
Available Online at www.ijarcs.info
}

\title{
AN IMPLEMENTATION OF RA-SCRUM TOOL DESIGN FOR FINDING THE REUSABILITY FUNCTION AND COMPONENT IN OBJECT ORIENTED LANGUAGE
}

\author{
P.Thenmozhi \\ Research Scholar, \\ Mother Teresa Women's University \\ Kodaikanal, India
}

\author{
Dr. P. Balasubramanie \\ Professor and Head, \\ Department of Computer Technology (PG) \\ Kongu Engineering College (Autonomous), Perundurai \\ India
}

\begin{abstract}
The software industries to release the product very quick and fast manner with respective of the customer requirements. Developer chooses the software engineering concept about the wide array of different project methods and models follow or even though design the product to their own styles by using of prototypes models. In any type of methods, the SCRUM models is the best approach for fast development of the application, and number of detail design process to solve as per requirement of the customer needs and analyzed at the begin of the project development by the scrum master and then script written understandable about the project design in step-by-step for team members and it is implemented by necessary coding and interface with tested mechanism as given of design specification for very fast delivery of the product.. But the major problem in scrum team is misunderstanding the requirement as well as risk factors in testing team. These factors are formulates to improve the communication and testing process, and to reduce the customer compliance, feedbacks, minimize delay in delivery of productivity and minimize cost and the risk factors in industry. In such way the developer creativity the software design in two ways, first to create the software code and another to develop the software tools for repeated application and such problem to minimize in way time , cost and to increase the quality of product by using the tool design in- variable risk effort is decrease for team members. Scrum methods are becoming too acceptable to design of software tool and much more flexible to customer practice and even changes process of the customer requirement ideas even late in the software project by team member, and these type of bendable facility available in RA-SCRUM Tool design methodology through scrum process, which one of the best method for reusability of the modules or function in the object oriented language. RA-SCRUM tool is best example for reusability of software codes, as most of the software industry is using this method.
\end{abstract}

Keywords: Agile -Scrum Process, RA-SCRUM Tools design, Risk Analysis, Adoptable Matching, Object Oriented Language.

\section{INTRODUCTION}

Today software development environment is very dynamic to writing the source code for various application even though it is a difficult with reference of the detail design and multiple skill set of developer to have the novelty changes of business tactics of new technology. Agile to perform the iterative and increment approach to develop the software of any application related to the style of the agile process as well as associated with scrum frame to reduce the development time, cost and work burden of the team, and quick product delivery of the end customer. Agile methods and process based on the multi-skilled individuals and team to showcase their ability in substantial domain knowledge for better understand of requirement given by customer. Agile team member and customer have an on-site relationship between them to the delivery of the product, and need the better understand software development of the project. Major issue of understanding of the project by process of the various stage of development life cycle match with requirement, process of the system, to verify and validation of data set, principles of design and work structure of the flow are difficult task to recognized with customer requirement than software tools, and better way of execute the task in automation for customer satisfy [1][2]. Software tools is shortcut methods for repeated process and to check the task in a routine manner [9] [10].

\section{TOOLS DESIGN AND DESCRIPTION STEPS FOR REUSABILITY}

Steps design 1: Reusability Requirement for Function Creation

The tool design to create the function development for source code for reusability transformation to the other environment adoptive to execute particular application or system project as show in the table 1.1.

Table 1.1 Reusability Requirement for Function Creation for railways reservation

\begin{tabular}{|c|l|}
\hline $\begin{array}{l}\text { S. } \\
\text { No. }\end{array}$ & \multicolumn{1}{|c|}{ Function Creation } \\
\hline 1. & void e-payment_shopping( ) \\
\hline 2. & void e-booking( ) \\
\hline 3. & void reservation_online( ) \\
\hline 4. & void card( ) \\
\hline 5. & void quota ( ) \\
\hline 6. & void complaint( ) \\
\hline
\end{tabular}

Totally six modules can have analysis for reusability transformation from one environment to other environment.

Steps design 2: Reusability Requirement for Function Selection from creation

Function selection is taken from predefined function existing in the old project, which is selected from the Reusability 
Requirement for Function Creation for railways reservation This is presented in Table 1.2.

Table 1.2 Reusability Requirement for Function Selection

\begin{tabular}{|c|l|l|}
\hline S,No. & \multicolumn{1}{|c|}{$\begin{array}{c}\text { Function } \\
\text { Selection }\end{array}$} & \multicolumn{1}{|c|}{$\begin{array}{c}\text { Predefine Function } \\
\text { Display }\end{array}$} \\
\hline 1. & divides & void divided() \\
\hline 2. & equal_to & void equal_to() \\
\hline 3. & Greater_than & void greater_equal() \\
\hline 4. & Greater & void greater() \\
\hline 5. & getch & void getche() \\
\hline 6. & println & void println() \\
\hline 7. & skip & void skip() \\
\hline
\end{tabular}

Various Function selections (Seven function) are taken from railway reservation software projects which are used as reusable components or function in the proposed projects reuse the code from one environment to other and it is obtainable in the Table1.3 as reusability requirement for Project Selection of railway source code [3][4].

Step design 3: Reusability Requirement for Project Selection railway source code.

The various Function selections (Table 1.2) which are taken from railway reservation software projects, to checked to find whether they have related to exact matches or parameter matches for reusability function or components of the new online railway reservation software environment in same organization and it is presented in the Table 1.3. for function selection.

Table 1.3 Reusability Requirement for Project Selection railway source code

\begin{tabular}{|c|c|c|l|}
\hline $\begin{array}{c}\text { S. } \\
\text { N } \\
\text { o. }\end{array}$ & projects & $\begin{array}{c}\text { Project } \\
\text { Selection }\end{array}$ & Function Selections \\
\hline 1. & $\begin{array}{c}\text { Railway } \\
\text { Reservation }\end{array}$ & $\begin{array}{c}\text { Projects } \\
\text { Irailway.cpp }\end{array}$ & $\begin{array}{l}\text { void pnr_status () } \\
\text { void helpline_online () } \\
\text { void chart( ) }\end{array}$ \\
\hline 2. & $\begin{array}{c}\text { Banking } \\
\text { System }\end{array}$ & $\begin{array}{c}\text { Projects } \\
\text { Ibanking.cpp }\end{array}$ & $\begin{array}{l}\text { void display_account } \\
\text { status () } \\
\text { void transaction( ) }\end{array}$ \\
\hline 3. & $\begin{array}{c}\text { Department } \\
\text { al store } \\
\text { system }\end{array}$ & $\begin{array}{c}\text { Projects } \\
\text { Idepartmenta } \\
\text { l.cpp }\end{array}$ & $\begin{array}{l}\text { void bill_copy () } \\
\text { void password_set () } \\
\text { void date () } \\
\text { void time () }\end{array}$ \\
\hline
\end{tabular}

The overall consulate reusability of function in Table1.4 and it representation in bar chart in figure1.1. for reusability for source code to other environmental.

\subsection{Formation of tools design of RA-SCRUM}

The sample documents desirable for RA-SCRUM model are detailed below in point wise of clear demonstration about the tools design. The following parameters and description are to be found and documented for various application which is related for accessing the source code is reliable to proposed application.

1. Total number of Tasks in the main project;

2. Sub tasks for main task project;

3. Secondary level tasks for every sub task;

4. Functions for every secondary level task;

5. Bench mark analysis

The above five point describe that the process is indicated for a sample project in Table 1.3. The minimum requirement bench marks are provided within brackets for software project. The bench marks value for functions or component clearly observed and show that less than $58 \%$ of reusable functions or component to eliminate that particular secondary sub task from main task. The producer for all secondary sub tasks should be completed in this systemic in fashionably. Similarly, the sequences step will continue to next sub task and will proceed further to the main task of the railway reservation software project [5][6].

\subsection{Outcome of Tool design}

The effective level adaptively and failure level nonadaptively for reusing the reusable component or functions that have been derived from various old projects to ensure adaptive reusability of functions in a new environmental software project (example railway reservation). These values are presented in Table 1.4. that can be show only the sample (few function is in table 1.4)

\section{Table 1.4 Impact Level of Adaptive Reusability}

\begin{tabular}{|c|c|c|c|c|}
\hline S.No & File name & $\begin{array}{l}\text { Function } \\
\text { components }\end{array}$ & $\begin{array}{l}\text { Effective Failure } \\
\text { Level (Effective }=1= \\
\text { Reusable, Failure } \\
=0=\text { Non reusable) }\end{array}$ & $\begin{array}{l}\text { Outcome } \\
\text { Respective to } \\
\text { Benchmark }\end{array}$ \\
\hline 1. & epayment.cpp & void Epayment & Reusable & Accepted \\
\hline 2. & ebooking.cpp & void $\mathrm{E}$ booking $($ ) & Reusable & Accepted \\
\hline 3. & reservation.cpp & $\begin{array}{l}\text { void Reservation } \\
\text { online } 0\end{array}$ & Reusable & Accepted \\
\hline 4. & complaint.cpp & void complaint() & Reusable & Accepted \\
\hline 5. & railway.cpp & void pur() & Reusable & Accepted \\
\hline 6. & railway.cpp & void belpline() & Reusable & Accepted \\
\hline & railway.cpp & void charti) & Reusable & Accepted \\
\hline 8. & banking cpp & void & Reusable & Accepted \\
\hline 9. & banking $c p p$ & void tramasction() & Reusable & Accepted \\
\hline 10. & department $c p p$ & void billo & Reusable & Accepted \\
\hline & departmental $c p p$ & void password() & $\begin{array}{l}\text { Reusabote } \\
\text { Reusable }\end{array}$ & Accepted \\
\hline$\frac{11}{12}$ & & & & \\
\hline 13. & transport cpp & $\begin{array}{l}\text { void } \\
\text { availability }\end{array}$ & Reusable & Accepted \\
\hline 14. & trangport $c g p$ & void waiting geat() & Reusable & Accepted \\
\hline 15. & transport cpp & $\begin{array}{l}\text { void } \\
\text { booking () luggage }\end{array}$ & Reusable & Accepted \\
\hline 16. & transport.cpp & void ticket & Reusable & Accepted \\
\hline
\end{tabular}

\section{ALGORITHM STEPS FOR REUSABILITY FOR RA-SCRUM TOOL DESIGN:}

A Function is created for the purpose of newly proposed project and this function can be integrated with an existing project is shown in Table 6.1. The steps involved in the process for determining the reusability are narrated below.

Sequence of steps for the solutions:

Step 1: Find out the functions or component in the new projects, that may be adapted relatively with reusable functions of the old software projects (Table 1.1).

Step 2: Identify reusable functions of the old projects for adaptation (Table 12).

Step 3: Segregate functions depending upon applications (Table 1.2).

Step 4: Group task dependent function components for appropriate adaptability (Table 1.3). 
Step 5: Analyze risk factors reusability through the RASCRUM model (Table 1.4).

The risk reduction can be achieved with the help of software reusability function or component which is enable entire systems with low level risk effect of vulnerability of the source code. Software project risk can be minimized slowly with software reusability adapted to environment where as applicable to all similar functionality systems [7][8]. The risk factor may lead to various possible upcoming risks level in the future code implementation of the modules. Software reusability is also helpful in analyzing the various possible functionalities of projects. Table 1.5 shows only the function which pertains to secondary such tasks using $\mathrm{C}$ ++ language. (sample).

Table 1.5 Consulate of reusability component Selection RA-SCRUM

\begin{tabular}{|c|l|c|c|c|c|}
\hline $\begin{array}{c}\text { S.N } \\
\text { o }\end{array}$ & File name & $\begin{array}{c}\text { No of } \\
\text { Functi } \\
\text { on or } \\
\text { compo } \\
\text { nent in } \\
\text { a file }\end{array}$ & $\begin{array}{c}\text { No of } \\
\text { Functi } \\
\text { on or } \\
\text { Compo } \\
\text { nents } \\
\text { require } \\
\text { d for } \\
\text { new } \\
\text { project }\end{array}$ & $\begin{array}{c}\text { Exact } \\
\text { Match }\end{array}$ & $\begin{array}{c}\text { Para } \\
\text { meter } \\
\text { Matc } \\
\text { h }\end{array}$ \\
\hline 1. & $\begin{array}{l}\text { employee.cp } \\
\text { p }\end{array}$ & 8 & 4 & 2 & 2 \\
\hline 2. & hotel.cpp & 10 & 3 & 1 & 2 \\
\hline 3. & $\begin{array}{l}\text { result } \\
\text { manage.cpp }\end{array}$ & 8 & 3 & 1 & 2 \\
\hline 4. & transport.cpp & 9 & 8 & 5 & 2 \\
\hline
\end{tabular}

This analyze packages which result in the reuse of various existing functions of an entire system. Risks can be greatly reduced by using software reusability function or component that are re-used in performing system functions. The bar chart for number of reusability used C++ for RA-SCRUM is a shown in figure 1.1.

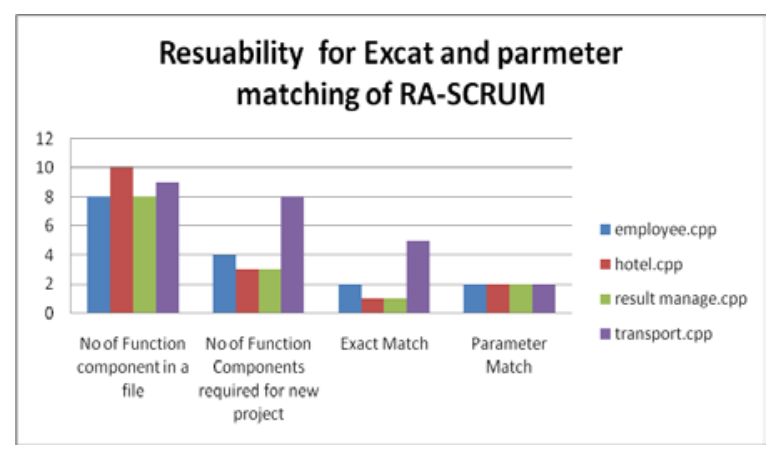

Figure 1.1 Bar chart for number of resuability used in Backlog ,Sprint and stories of RA-SCRUM

3.1 Level of Reusablity in RA-SCRUM Based on Tool Design

The reusability function in $\mathrm{C}++$, to implementing in $\mathrm{RA}$ SCRUM B abased on the scrum process. In CASE 1, tables 6.3,6.4 and 6.5 converting in RA-SCRUM, as given below table 1.6.
Table1.6 Level of Reusability with respective of Product Backlog, Sprint and stories of RASCRUM

\begin{tabular}{|c|c|c|c|c|c|}
\hline $\begin{array}{l}\text { Product } \\
\text { backlog }\end{array}$ & $\begin{array}{l}\text { ID of } \\
\text { Procusuct } \\
\text { becklog }\end{array}$ & Sprint backlog & $\begin{array}{l}\text { Number } \\
\text { of apring } \\
\text { backlog }\end{array}$ & Stories in sprint & $\begin{array}{l}\text { Number } \\
\text { of stories }\end{array}$ \\
\hline $\begin{array}{l}\text { Employ } \\
\text { pe } \\
\text { product }\end{array}$ & A & $\begin{array}{l}\text { 1. void insert } \\
\text { 2. void deletes } \\
\text { 3. void search } \\
\text { 4. void sort } \\
\text { vort }\end{array}$ & 4 Sprint & $\begin{array}{l}\text { 1. vold buald } \\
\text { 2. void list } \\
\text { 3. void insert } \\
\text { 4. void deletes } \\
\text { 5. void edit } \\
\text { 6. void search } \\
\text { 7. void sour } \\
\text { 8. void neemu }\end{array}$ & \& Stories \\
\hline$\underset{\text { produsct }}{\text { Hotel }}$ & B & $\begin{array}{l}\text { 1. void booksing } \\
\text { 3. vood Caucellation } \\
\text { void restaurant }\end{array}$ & 3 Sprint & 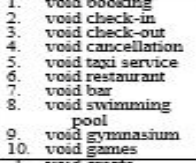 & $\begin{array}{c}10 \\
\text { Stories }\end{array}$ \\
\hline $\begin{array}{l}\text { Result } \\
\text { manage } \\
\text { product }\end{array}$ & c & $\begin{array}{l}\text { 1. void modify } \\
\text { 2. void concession } \\
\text { 3. void primt }\end{array}$ & 3 Sprinet & $\begin{array}{l}\text { 1. vold create } \\
\text { 2. vood add } \\
\text { 4. vood search } \\
\text { 4. vood modify. } \\
\text { 6. vood merit } \\
\text { 6. vood delete } \\
\text { 8. vood concession } \\
\text { 8. voint }\end{array}$ & \& Stories \\
\hline $\begin{array}{l}\text { Trenapo } \\
\text { It } \\
\text { product }\end{array}$ & D & $\begin{array}{l}\text { 1. vold reservation } \\
\text { 2. void seat } \\
\text { 3. void wailabilitity } \\
\text { 4. void suat } \\
\text { bogage } \\
\text { bogking }\end{array}$ & 8 Spribt & $\begin{array}{l}\text { 1. woud reservabon } \\
\text { 2. void seat arability } \\
\text { 3. void waiting, seat } \\
\text { 4. void huggage- } \\
\text { booking- } \\
\text { 5. void ticket } \\
\text { akrailability }\end{array}$ & 9 Stories \\
\hline
\end{tabular}

Software reusability is also supportive to analyzing the different potential functionalities and suitability of given requirement without major modification, such way of the 1 RA-SCRUM is used to implement in $\mathrm{C}++$ with reference of tool implement design of reusability. In same tool, the implementation design can be applied in the scrum processing (that is RA-SCRUM) based on product backlog, sprint and stories. Each product backlog named as ID of A, $\mathrm{B}, \mathrm{C}, \mathrm{D}$ respectively and same for the sprint and stories, that it converting into consultant the values for marked to plat the bar chart of RA-SCRUM in figure 1.2.

Table 6.8 Consulate Reusability function or Component Selection using BACKLOG, SPRINT and STORIES in RA-SCRUM.

\begin{tabular}{|c|c|c|c|c|}
\hline $\begin{array}{c}\text { ID of } \\
\text { Product } \\
\text { backlog }\end{array}$ & $\begin{array}{l}\text { Number } \\
\text { of sprint } \\
\text { backlog }\end{array}$ & $\begin{array}{l}\text { Number } \\
\text { of stories }\end{array}$ & $\begin{array}{c}\text { Exact } \\
\text { matching }\end{array}$ & $\begin{array}{c}\text { Parameter } \\
\text { matching }\end{array}$ \\
\hline A & 4 & 8 & 2 & 2 \\
\hline B & 3 & 1 & 1 & 2 \\
\hline C & 3 & 8 & 1 & 2 \\
\hline D & 8 & 9 & 5 & 2 \\
\hline
\end{tabular}

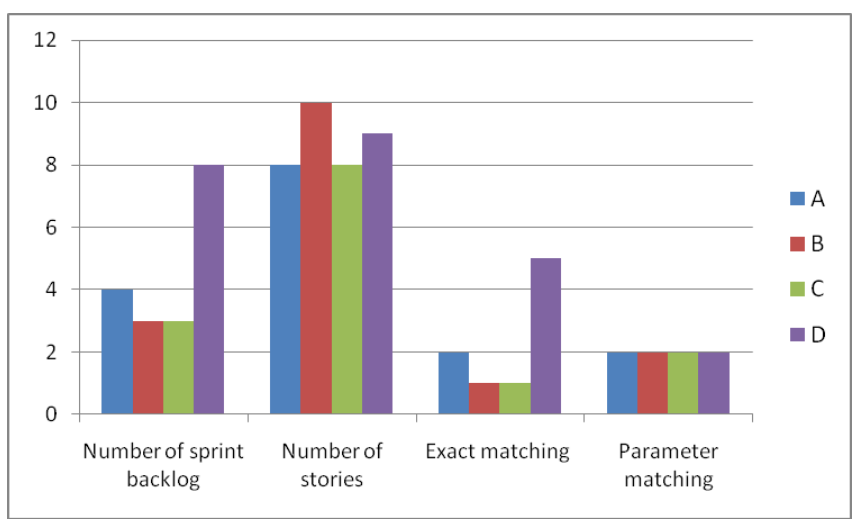

Figure 1.2: Bar chart for number of resuability used in Backlog ,Sprint and stories of RA-SCRUM

The exacts matching and parameter matching bar char same, due process based on $\mathrm{C}++$ and the same process are converting into scrum process of case one of RA-SCRUM. 


\section{RESULT AND DISCUSSION OF RA-SCRUM TOOL DESIGN:}

The RA-SCRUM tool design based on which classified into three tools for making the reusability function component.

Tool 1: F Copy, RA-SCRUM tools to found that the copy of file source to designation file using visual studio development of (Visual Studio 2013), on Window XP operating system.

Tool 2: F Compare, after transferring the source file to designation, the comparison the two file which adopted file with designation file about the line of code and bytes, whether the transfer is adaptable or not reusability.

Tool 3: RA, after comparing of reusability file, it can be check and list out the abstract classes, Methods, base classes and sealed classes whether the reusable component are adopted or not. The tool design outcome is shown in below with explanation with result base on visual studio 2013.

\subsection{Result of Tools design 1: F Copy:}

The selected files source folder to destination folder for reusability check of output 1 and output 2 in following screen shot.

Output 1: Selection of source file of FCopy.

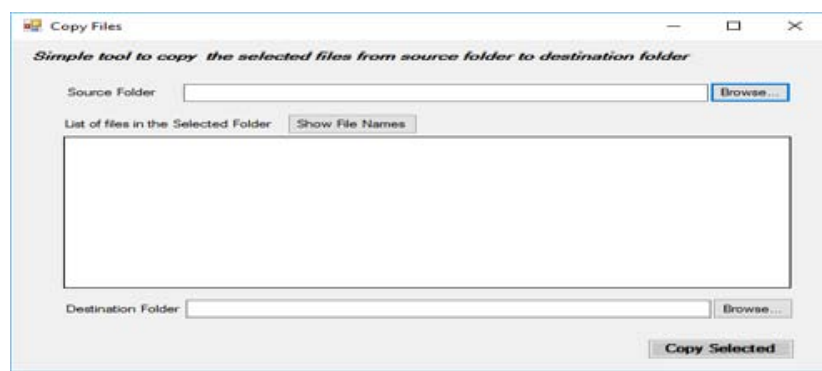

Output 2: selection file to destination file for reusability in other location

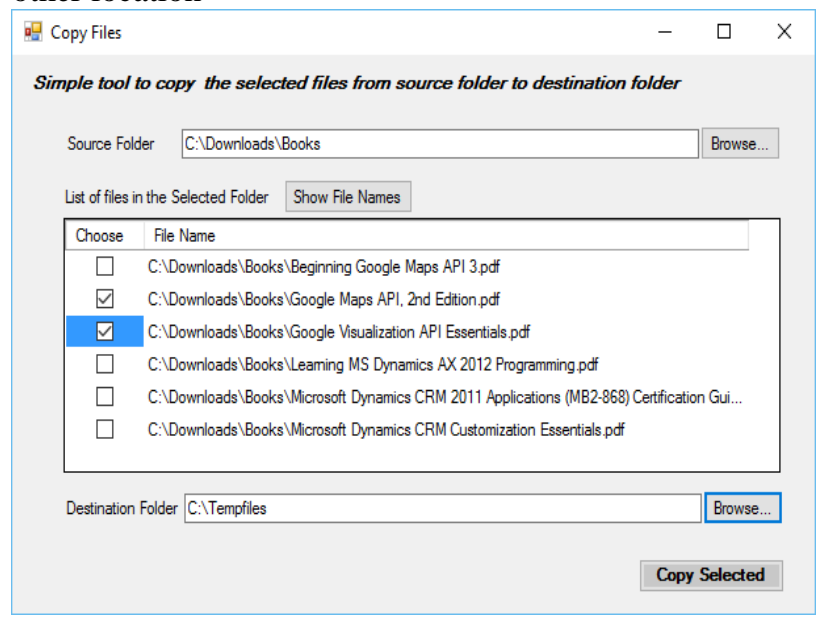

\subsection{Result of Tool design2: F Compare:}

The selection of two file which file is transfer from source to destination reusability file for checking the adaptability and list the line of code and bytes of source code.

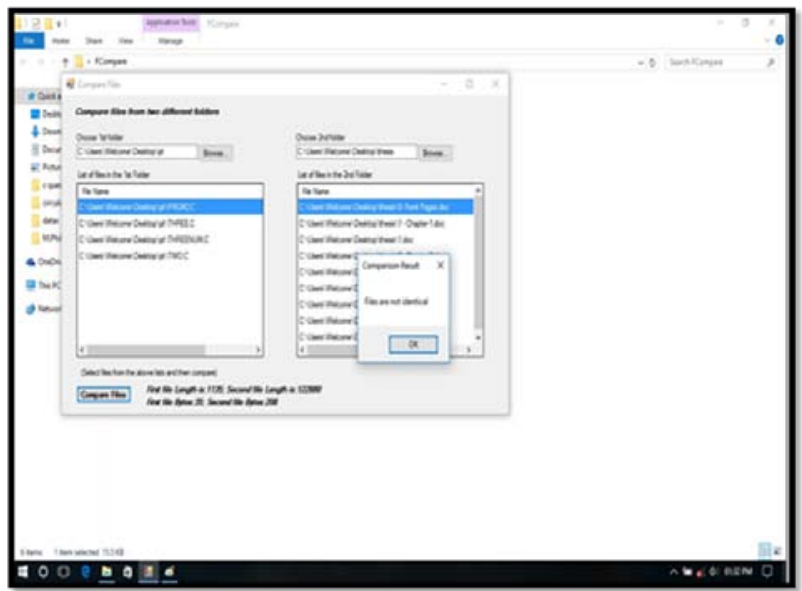

4.3 Result of Tools design 3: RA: Program for Finding the Reusability Component of Abstract Class and Base Class:

Step 1: Software code written visual programming language for finding the square box as: Program for Finding the Reusability Component of Abstract Class and Base Class as given below screen shot.

Output of Convert source into assembly language, and again convert into .exe file for run the Program

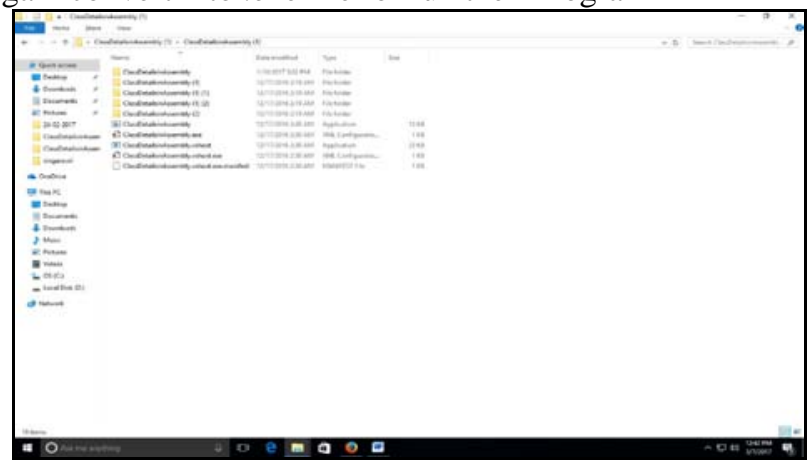

Step 2: Run the program in visual studio, the following output for the startup menu tool bar with FILE, EDIT, DUBUG, TEAM, TEST etc.,

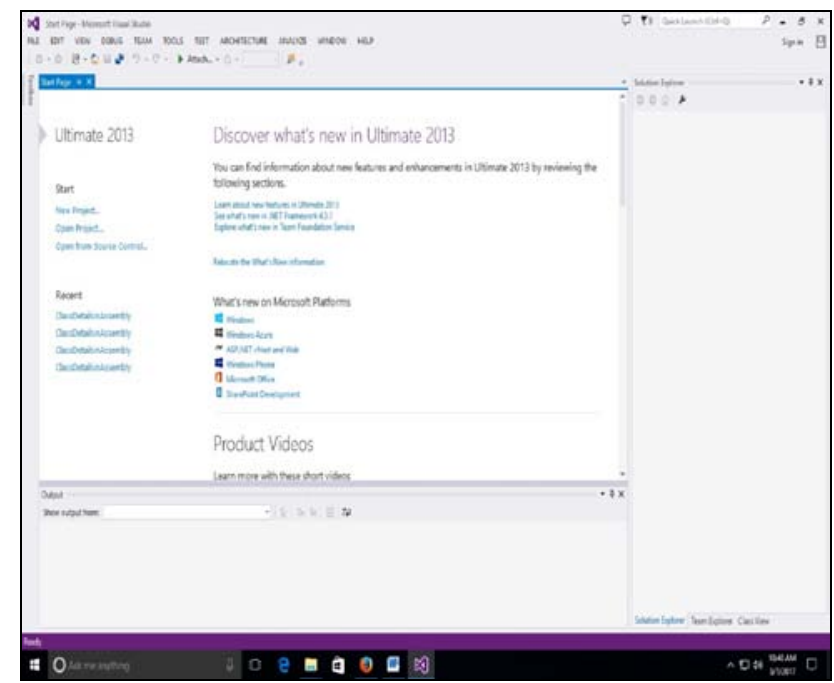




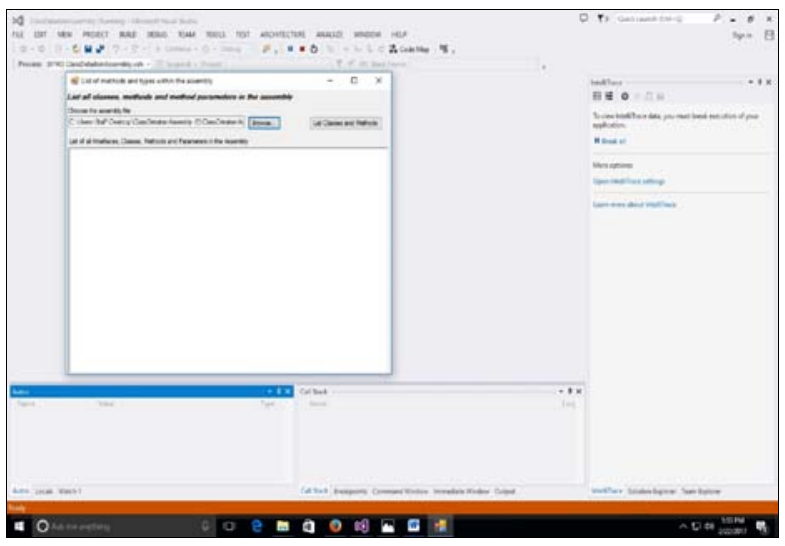

Step 3: Software code run in visual studio, pick up run file is .exe from the drive through browse for list the classes and methods of given software codes.

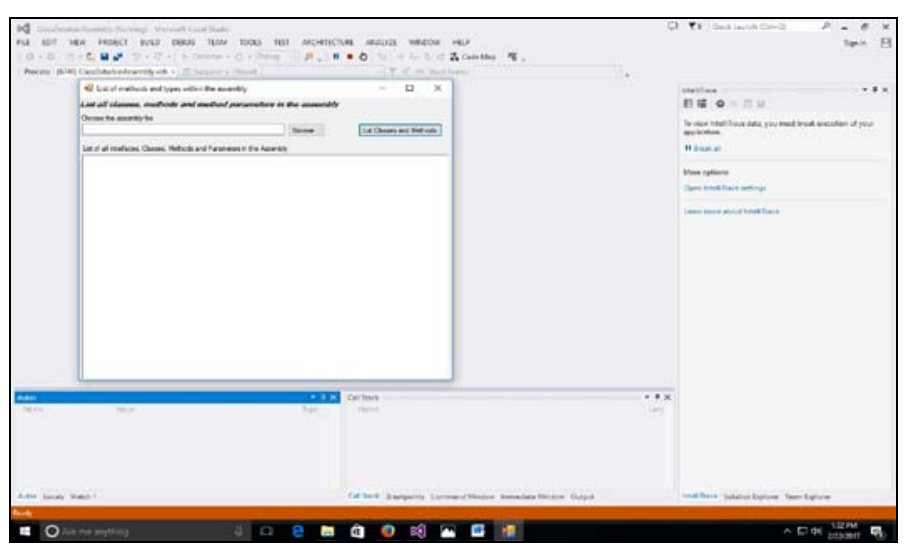

Step 4: Output for the Step 1 for lit out the classes and methods of the software code which first convert into assembly language and convert into the code able form in visual programming is shown in below.

\section{Output 1: Public Classes and Methods for RA-SCRUM}

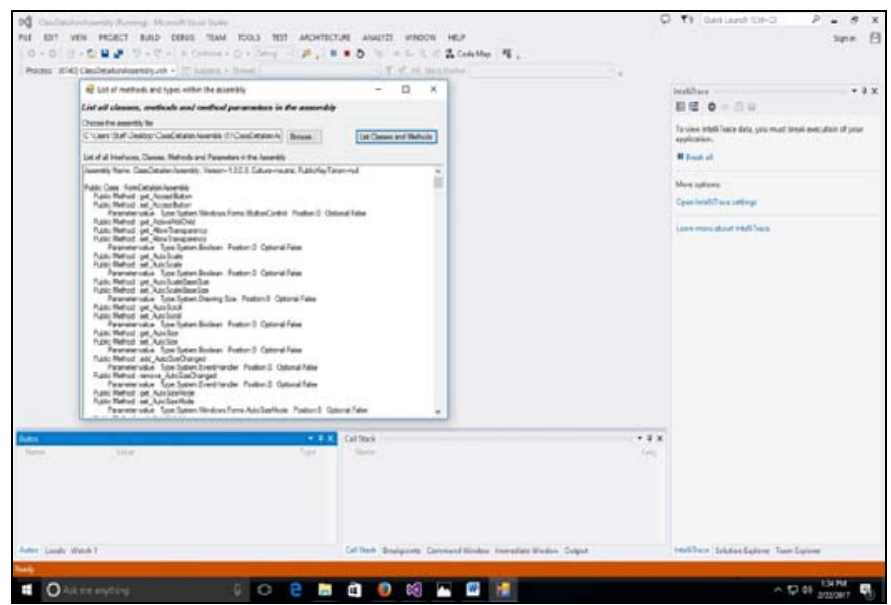

Output 2: Abstract Classes: Program and Sealed Class: Settings for RA-SCRUM

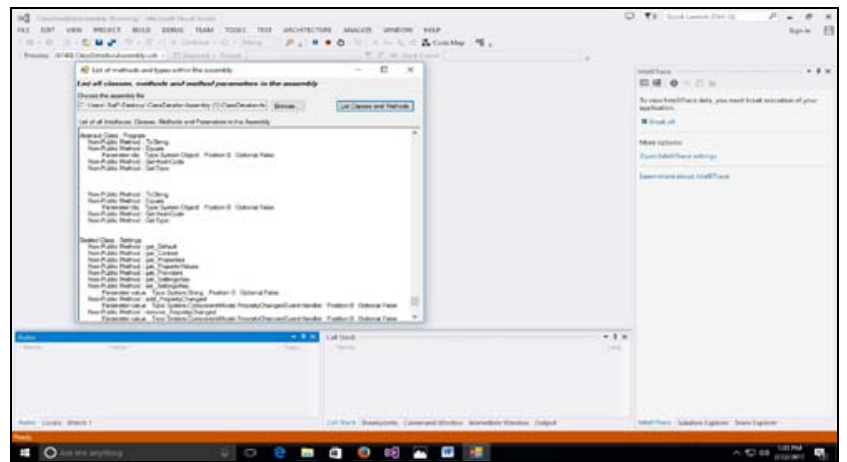

The RA-SCRUM tool design shown the various output as result of design for reusability for converting the function or component of reused source code of modules which is similar from one environment to other environment whether to check the reusability source code is suitability and adaptively another, if it not non adaptively to checking mechanism to help them to find the risk factor to minimize to reduce the defect and vulnerability which are not affect in future, these analysis is made in the thought out this research article is demonstrated and design as tool implementation in visual basic studio and through this tools design to valuated and verification done with helps of RA-SCRUM tool design as well as to compare with various tool design like orange scrum and it is better way of using this tools design.

\section{REFERENCES:}

[1]. Ali Raza Ahmed, Muhammad Tayyab, Shahid Nazir Bhatti, Abdullah J. Alzahrani and Muhammad Imran Babar 2017, 'Impact of Story Point Estimation on Product using Metrics in Scrum Development Process', (IJACSA) International Journal of Advanced Computer Science and Applications, Vol.8, No.4, pp 385- 391.

[2]. Benjamin Gold and Clive Vassell 2016, 'Using Risk Management to Balance Agile Methods, A study of the Scrum process' International Journal of Mechatronics, Electrical and Computer Technology, Vol. 6., no.21, PP. 2943-2950.

[3]. Chhavi Malhotra \& Anuradha Chug 2013, 'Agile Testing with Scrum- A Survey’, vol. 3, Issue 3, ISSN: 2277 128X.

[4]. Dyba, T \& Dingsoyr, T 2008, 'Empirical studies of agile software development: A systematic review', Inf Softw Technol., vol. 50, no. 9- 10, pp. 833-859.

[5]. Edzreena Odzaly, DG 2014, 'Lightweight Risk Management in Agile Projects', Proc. Int. Conf. Softw.Eng. Knowledge Engineering, vol. 26, pp. 576- 581.

[6]. Rabeeah Jabeen and Mohammad Daud Awan 2016, 'Role of Risk Management in Scrum', Communications on Applied Electronics (CAE) - ISSN: 2394-4714, Vol. 4., No.6, pp18-22.

[7]. Roland Petrarch 2014, 'Agile Project Management with Scrum: Extension Points', International Conference on challenges in IT, Engineering and Technology (ICCIET'2014) Phuket (Thailand).

[8]. Sara A shraf and Shabib Aftab 2017, 'IScrum: An Improved Scrum Process Model', International Journal Modern Education and Computer Science, Vol.8., pp16-24.

[9]. Juyun Cho 2011, 'Management Guidelines for Scrum Agile Software Development Process', (IJCIS), vol. 12, no. 1, pp. 213-223.

[10].UzairIqbal \& Ali Javed 2014, 'Review-Scrum(R-Scrum) Introduction of Model Driven Architecture (MDA) In Agile Methodology', International Journal of Scientific \& Technology Research, vol. 3, Issue 11, ISSN 2277-8616. 